\title{
REVIEW
}

\section{Kidney health for everyone everywhere - from prevention to detection and equitable access to care}

\begin{abstract}
Philip Kam-Tao Li', Guillermo Garcia-Garcia², Siu-Fai Lui', Sharon Andreoli, Winston Wing-Shing Fung', Anne Hradsky Latha Kumaraswami ${ }^{6}$. Vassilios Liakopoulos ${ }^{7}$, Ziyoda Rakhimova ${ }^{5}$, Gamal Saadi ${ }^{8}$, Luisa Strani ${ }^{5}$, Ifeoma Ulasi', Kamyar Kalantar-Zadeh ${ }^{10}$, for the World Kidney Day Steering Committee 'Department of Medicine and Therapeutics, Carol \& Richard Yu PD Research Centre, Prince of Wales Hospital, Chinese University of Hong Kong, Hong Kong; ${ }^{2}$ Nephrology Service, Hospital Civil de Guadalajara Fray Antonio Alcalde, University of Guadalajara Health Sciences Center, Guadalajara, Jal., Mexico; ${ }^{3}$ Division of Health System, Policy and Management, Jockey Club School of Public Health and Primary Care, The Chinese University of Hong Kong, Hong Kong; ${ }^{4}$ James Whitcomb Riley Hospital for Children, Indiana University School of Medicine, Indianapolis, USA; ${ }^{5}$ World Kidney Day Office, Avenue des Arts 1-2, 6th floor, B- 121 0, Brussels, Belgium; ${ }^{6}$ Tanker Foundation, Chennai, India; 'Division of Nephrology and Hypertension, I st Department of Internal Medicine, AHEPA Hospital, Aristotle University of Thessaloniki, Thessaloniki, Greece; ${ }^{2}$ Nephrology Unit, Department of Internal Medicine, Faculty of Medicine, Cairo University, Giza, Egypt; ${ }^{9}$ Renal Unit, Department of Medicine, College of Medicine, University of Nigeria, Ituku-Ozalla, Enugu, Nigeria; ${ }^{10}$ Division of Nephrology and Hypertension and Kidney Transplantation, University of California Irvine School of Medicine, Orange, CA, USA.
\end{abstract}

\section{ABSTRACT}

The global burden of chronic kidney disease (CKD) is rapidly increasing, with a projection of becoming the 5th most common cause of years of life lost globally by 2040. Aggravatingly, CKD is a major cause of catastrophic health expenditure. The costs of dialysis and transplantation consume up to $3 \%$ of the annual healthcare budget in highincome countries. Crucially, however, the onset and progression of CKD is often preventable. In 2020, the World Kidney Day campaign highlights the importance of preventive interventions - be it primary, secondary or tertiary. This article focuses on outlining and analyzing measures that can be implemented in every country to promote and advance CKD prevention. Primary prevention of kidney disease should focus on the modification of risk factors and addressing structural abnormalities of the kidney and urinary tract, as well as exposure to environmental risk factors and nephrotoxins. In persons with pre-existing kidney disease, secondary prevention, including blood pressure optimization and glycemic control, should be the main goal of education and clinical interventions. In patients with advanced CKD, management of co-morbidities such as cardiovascular disease is a highly recommended preventative intervention to avoid or delay dialysis or kidney transplantation. Political efforts are needed to support the preventive approach. While national policies and strategies for non-communicable diseases might be present in a country, specific policies directed toward education and awareness about CKD screening, management and treatment are often lacking. Hence, there is an urgent need to increase the awareness of the importance of preventive measures among populations, professionals and policy makers.

Keywords: World Kidney Day; chronic kidney disease.

\section{INTRODUCTION}

Around 850 million people currently are affected by different types of kidney disorders [I]. Up to one in ten adults worldwide has chronic kidney disease (CKD), which is invariably irreversible and mostly progressive.
The global burden of CKD is increasing, and CKD is projected to become the 5 th most common cause of years of life lost globally by 2040 [2]. If CKD remains uncontrolled and if the affected person survives the

Received 10 February 2020; published 10 March 2020.

Correspondence: Philip KT Li, philipli@cuhk.edu.hk, and K Kalantar-Zadeh, kkz@uci.edu.

(C)2020 World Kidney Day Steering Committee. Published under a Creative Commons Attribution 4.0 International License. 
ravages of the cardiovascular and other complications of the disease, CKD progresses to end-stage renal disease (ESRD), where life cannot be sustained without dialysis therapy or kidney transplantation. Hence, CKD is a major cause of catastrophic health expenditure [3]. The costs of dialysis and transplantation consume $2-3 \%$ of the annual healthcare budget in high-income countries, spent on less than $0.03 \%$ of the total population of these countries [4].

Importantly, however, kidney disease can be prevented and progression to ESRD can be delayed with appropriate access to basic diagnostics and early treatment including lifestyle modifications and nutritional interventions [4-8]. Despite this, access to effective and sustainable kidney care remains highly inequitable across the world, with kidney disease a low health priority in many countries. Kidney disease is crucially missing from the international agenda for global health. It is notably absent from the impact indicators for the Sustainable Development Goal (SDG) Goal 3, Target 3.4. "By 2030, reduce by one third premature mortality from non-communicable diseases (NCDs) through prevention and treatment and promote mental health and well-being," and the latest iteration of the United Nations Political Declaration on NCDs [9]. Current global political commitments on NCDs focus largely on four main diseases: cardiovascular disease (CVD), cancer, diabetes, and chronic respiratory diseases. Yet, it is estimated that $55 \%$ of the global NCD burden is attributed to diseases outside of this group [10]. Furthermore, kidney disease frequently co-exists with the 'big four' NCDs, which leads to worse health outcomes. CKD is a major risk factor for heart disease and cardiac death, as well as for infections such as tuberculosis, and is a major complication of other preventable and treatable conditions including diabetes, hypertension, HIV infection and hepatitis [4-7]. As the Sustainable Development Goals (SDG) and Universal Health Coverage (UHC) agendas progress and provide a platform for raising awareness of NCDs, targeted action on kidney disease prevention should become integral to the global policy response [I]. The global kidney health community calls for the recognition of kidney disease, effective identification and management of its risk factors and the implementation of an integrated and peoplecentered approach to care.

\section{DEFINITION AND CLASSIFICATION OF CKD PREVENTION}

According to expert definitions, including that of the Centers for Disease Control and Prevention [ I I ], the term "prevention" refers to activities that are typically categorized by the following three definitions: (i) primary prevention implies intervening before health effects occur in an effort to prevent the onset of illness or injury before the disease process begins, (ii) secondary prevention suggests preventive measures that lead to early diagnosis and prompt treatment of a disease to prevent more severe problems developing and includes screening to identify diseases in the earliest stages, and (iii) tertiary prevention indicates managing disease after it is well established in order to control disease progression and the emergence of more severe complications, which is often by means of targeted measures such as pharmacotherapy, rehabilitation, and screening for and management of complications. These definitions have important bearing on the prevention and management of the CKD, and accurate identification of risk factors that cause CKD or lead to faster progression to renal failure, as shown in Figure I, are relevant in health policy decisions and health education and awareness related to CKD [12].

\section{PRIMARY PREVENTION OF CKD}

Measures to achieve effective primary prevention should focus on the two leading risk factors for CKD, diabetes mellitus and hypertension. Other CKD risk factors include polycystic kidneys or other congenital or acquired structural anomalies of the kidney and urinary tract, primary glomerulonephritis, exposure to nephrotoxic substances or medications (such as nonsteroidal anti-inflammatory drugs), having one single kidney (for example, after cancer nephrectomy), high dietary salt intake, inadequate hydration with recurrent volume depletion, heat stress, exposure to pesticides and heavy metals (as has been speculated as the main cause of Mesoamerican nephropathy), and possibly high protein intake in those at higher risk of CKD [8]. Among non-modifiable risk factors are advancing age and genetic factors such as apolipoprotein I (APOLI) gene variants mostly encountered in those with sub-Saharan African ethnicity, especially among African Americans. Table I shows some of the risk factors of CKD.

Among measures to prevent emergence of de novo CKD are screening efforts to identify and manage persons at high risk of CKD, especially those with diabetes mellitus and hypertension. Hence, targeting primordial risk factors of these two conditions including metabolic syndrome and overnutrition is relevant to primary CKD prevention, as is correcting obesity [14]. Promoting healthier lifestyles is an important means to that end including physical activity and healthier diet. The latter should be based on more plantbased foods with less meat, less sodium intake, more complex carbohydrates with higher fiber intake, and less saturated fat. In those with hypertension and diabetes, optimizing blood pressure and glycemic control has shown to be effective in preventing diabetic and hypertensive nephropathies. Persons with a solitary kidney should avoid high protein intake above I gram per kilogram body weight 
PRIMARY CKD PREVENTION

RISK FACTORS

Obesity, diabetes, hypertension, polycystic kidneys, solitary kidney, high-salt high protein intake, inadequate hydration, genetics (APOLI), other risk factors

GECONDARY PREVENTION
I. Slowing CKD progression, 2. Delaying/deferring
dialysis transition
RISK FACTORS
Uncontrolled hypertension, high protein high-salt diet,
acidosis, AKI events
GOAL
TERTIARY PREVENTION
Management of uremic symptoms and comorbidities
(anemia, acidosis, mineral-bone disorders, fluid overload,
cardiovascular disease \& mortality, protein-energy wasting)
Declining GFR
Renal hyperfiltration

Identify high risk persons, manage obesity, improve glycemic \& BP control, avoid high salt diet, encourage healthy food and lifestyle

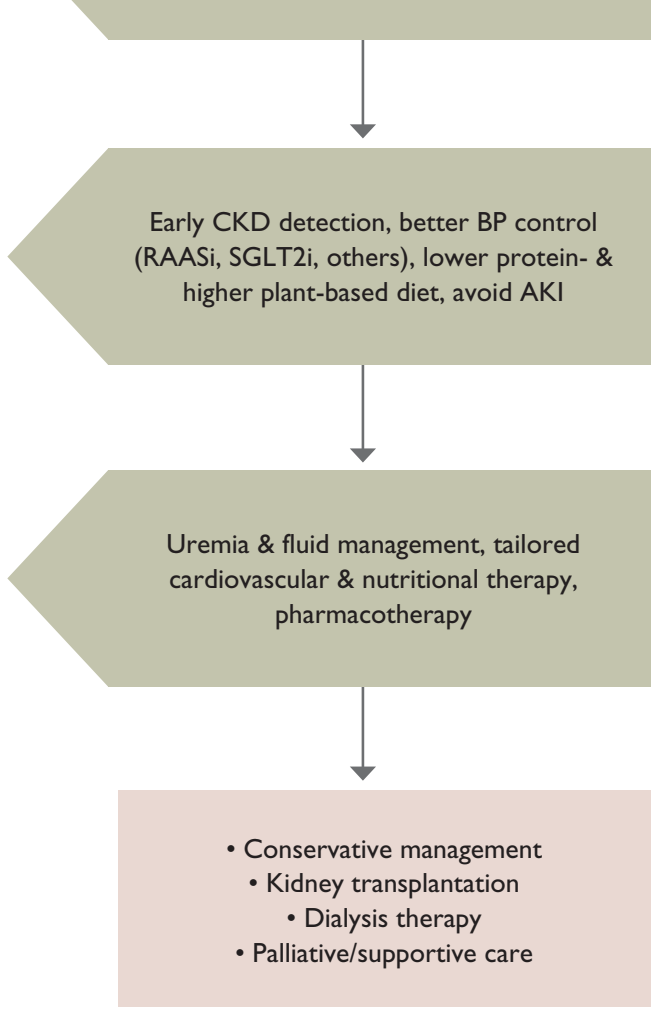

Figure I. Overview of the preventive measures in chronic kidney disease (CKD) to highlight the similarities and distinctions pertaining to primary, secondary, and tertiary preventive measures and their intended goals. Abbreviations:AKI, acute kidney injury; BP, blood pressure; GFR, glomerular filtration rate; RAASi, renin-angiotensin-aldosterone system inhibitors; SGLT2i, sodium-glucose cotransporter-2 inhibitors.

per day [15]. Obesity should be avoided, and weight reduction strategies should be considered [14].

\section{SECONDARY PREVENTION IN CKD}

Evidence suggests that among those with CKD, the vast majority have early stages of the disease, that is, CKD stages I and 2 with albuminuria or CKD stage 3A (estimated glomerular filtration rate (eGFR) of 45 to $59 \mathrm{~mL} /$ $\mathrm{min} / 1.73 \mathrm{~m}^{2}$ ) [16]. For these earlier stages of CKD, the main goal of kidney health education and clinical interventions is to slow disease progression. Uncontrolled or poorly controlled hypertension is one of the most established risk factors for faster CKD progression.

The cornerstone of the pharmacotherapy in secondary prevention is the renin-angiotensin-aldosterone system inhibitors (RAASi). Low protein diet appears to have a synergistic effect on RAASi therapy [17]. Recent data suggest that a new class of anti-diabetic medications known as sodium-glucose cotransporter-2 inhibitors can slow CKD progression, and this effect may not be related to glycemic modulation by the medication. Whereas acute kidney injury (AKI) may or may not cause de novo CKD, $A K I$ events that are superimposed on preexisting CKD may accelerate disease progression [ 18]. A relatively recent case of successful secondary prevention that highlights the significance of implementing preventive strategies in CKD is the use of vasopressin receptor antagonists in adult polycystic kidney disease [19].

\section{TERTIARY PREVENTION IN CKD}

In patients with advanced CKD, management of uremia and related comorbid conditions such as anemia, mineral and bone disorders, and cardiovascular disease is of high priority, so that these patients can continue to achieve the 
Table I. Risk factors for de novo CKD and pre-existing CKD progression.

\begin{tabular}{|c|c|c|}
\hline Risk factor & Contribution to de novo CKD & Contribution to CKD progression \\
\hline Diabetes mellitus & Approximately $50 \%$ of all CKD & \\
\hline Hypertension & Approximately $25 \%$ of all CKD & \\
\hline Obesity & $10-20 \%$ & \\
\hline Age & $\begin{array}{l}\text { Seen with advancing age, especially in the setting } \\
\text { of comorbid conditions }\end{array}$ & $\begin{array}{l}\text { Some evidence suggests that older patients may } \\
\text { have slower progression. }\end{array}$ \\
\hline $\begin{array}{l}\text { Race, genetics and other hereditary factors: } \\
\text { - APOLI gene } \\
\text { - Hereditary nephritis (Alport's) }\end{array}$ & $\begin{array}{l}\text { Common among those with African American } \\
\text { ancestors }\end{array}$ & \\
\hline $\begin{array}{l}\text { Acute glomerulonephritis: } \\
\text { - Post-infectious GN } \\
\text { - Rapidly progressive GN }\end{array}$ & $<10 \%$ & Recurrent GN or exacerbation of proteinuria \\
\hline Polycystic kidney disorders & $<10 \%$, family history of cystic kidney disorders & \\
\hline $\begin{array}{l}\text { AKI } \\
\text { - ATN } \\
\text { - Acute interstitial nephritis }\end{array}$ & Repeated AKI bouts can cause CKD & $\begin{array}{l}\text { Repeated AKI bouts can accelerate CKD } \\
\text { progression }\end{array}$ \\
\hline \multicolumn{3}{|l|}{$\begin{array}{l}\text { Autoimmune disorders } \\
\text { - Lupus erythematosus } \\
\text { - Other connective tissue disorders }\end{array}$} \\
\hline $\begin{array}{l}\text { Pharmacologic: } \\
\text { - Medications causing interstitial nephritides } \\
\text { (NSAIDS, calcineurin inhibitirs, chemotherapy, } \\
\text { PPIs, etc.) or ATN (aminoglycosides) } \\
\text { - Herbs and herbal medication }\end{array}$ & $\begin{array}{l}\text { Variable, e.g., in Taiwan, Chinese herb } \\
\text { nephropathy may be an important contributor }\end{array}$ & \\
\hline $\begin{array}{l}\text { Environmental: } \\
\text { • Heavy metal exposure }\end{array}$ & Rare & \\
\hline \multicolumn{3}{|l|}{$\begin{array}{l}\text { Acquired or congenital solitary kidney } \\
\text { - Cancer, donor or traumatic nephrectomy } \\
\text { - Congenital solitary kidney, unilateral atrophic } \\
\text { kidney }\end{array}$} \\
\hline $\begin{array}{l}\text { Acquired urinary tract disorders \& obstructive } \\
\text { nephropathy }\end{array}$ & $\begin{array}{l}\text { Benign prostatic hypertrophy and prostate } \\
\text { cancer in men, gynecologic cancers in women }\end{array}$ & \\
\hline $\begin{array}{l}\text { Congenital anomalies of the kidney and } \\
\text { urinary tract }\end{array}$ & Mostly in children and young adults & \\
\hline $\begin{array}{l}\text { Inadequate fluid intake } \\
\text { - Mesoamerican nephropathy } \\
\text { - Others }\end{array}$ & $\begin{array}{l}\text { Unknown risk, but high prevalence is suspected } \\
\text { in Central America }\end{array}$ & $\begin{array}{l}\text { Whereas in earlier CKD stages adequate } \\
\text { hydration is important to avoid pre-renal AKI, } \\
\text { higher fluid intake in more advanced CKD may } \\
\text { increase the risk of hyponatremia }\end{array}$ \\
\hline High protein intake & $\begin{array}{l}\text { Unknown risk, recent data suggest higher CKD } \\
\text { risk or faster CKD progression with high protein } \\
\text { diet, in particular, from animal sources }\end{array}$ & $\begin{array}{l}\text { Higher protein intake can accelerate the rate of } \\
\text { CKD progression }\end{array}$ \\
\hline Cardiovascular diseases (cardiorenal) & Ischemic nephropathy & \\
\hline Liver disease (hepatorenal) & NASH cirrhosis, viral hepatitis & \\
\hline $\begin{array}{l}\text { Malignancy (myeloma, light chain deposition } \\
\text { disease, AL amyloidosis, etc.) }\end{array}$ & & \\
\hline
\end{tabular}

Abbreviations: AKI, acute kidney injury; AL, amyloid light-chain; ATN, acute tubular necrosis; CKD, chronic kidney disease; GN, glomerulonephritis; NASH, nonalcoholic steatohepatitis; NSAID, nonsteroidal anti-inflammatory drug; PPI, proton pump inhibitor.

Many of these risk factors contribute to both de novo CKD and its faster progression and hence are relevant to both primary and secondary prevention.

highest longevity. These measures can be collectively referred to as "tertiary prevention" of CKD. Whereas many of these patients will eventually receive renal replacement therapy in form of dialysis or kidney transplantation, a new trend is emerging to maintain them for longer without dialysis by implementing conservative management of CKD.

\section{APPROACHES TO IDENTIFICATION OF CHRONIC KIDNEY DISEASES}

The lack of awareness of CKD around the world is one of the reasons for late presentation of CKD in both developed and developing economies [20-22]. The overall CKD 
awareness among the general population and even high cardiovascular risk groups across 12 low-income and middle-income countries was less than 10\% [22].

Given its asymptomatic nature, screening for CKD plays an important role in early detection. Consensus and position statements have been published by the International Society of Nephrology [23], National Kidney Foundation [24], Kidney Disease Improving Global Outcomes (KDIGO) [25], NICE Guidelines [26] and Asian Forum for CKD Initiatives [27]. There is a lack of trials evaluating the screening and monitoring of CKD [28]. Currently most guidelines will promote a targeted screening approach to early detection of CKD. Some of the major groups at risk for targeted screening are patients with diabetes and hypertension, those with a family history of CKD, individuals receiving potentially nephrotoxic drugs or herbal medicines, patients with a past history of acute kidney injury and individuals older than 65 years [27,29]. CKD can be detected with two simple tests, a urine test $f$ or the detection of proteinuria and a blood test to estimate GFR [24,27].

Currently, population screening for CKD is not recommended [28, 30]. Low- to middle-income countries are illequipped to deal with the devastating consequences of CKD, particularly the late stages of the disease, and therefore effective preventative measures to avoid CKD or slow progression are of immense importance in these regions. There are suggestions that screening should primarily include high-risk individuals, but also extend to those with lower levels of risk, for example, those individuals with prediabetes and prehypertension [3I].

\section{COST-EFFECTIVENESS OF EARLY DETECTION PROGRAMS}

Universal screening of the general population would be time-consuming, expensive and not cost-effective, unless selectively directed towards high- risk groups [32-35]. The approach towards CKD early detection will include the decision for frequency of screening, who should perform the screening and intervention after screening [2I]. Screening frequency for targeted individuals should be yearly if no abnormality is detected on initial evaluation. This is in line with the KDIGO guideline [25]. Patients detected to have CKD should be referred to primary care and general physicians with experience in management of kidney disease for follow up. Further referral to nephrologists for management will be based on the well-defined pro| tocols [22,25,27].

\section{INTEGRATION OF CKD PREVENTION INTO NATIONAL NCD PROGRAMS}

Given the close links between CKD and other NCDs, it is critical that CKD advocacy efforts be aligned with existing initiatives concerning diabetes, hypertension, and cardiovascular disease, particularly in low- and middle-income countries. Some countries and regions have successfully introduced CKD prevention strategies as part of their NCD programs. As an example, in 2003, a kidney health promotion program was introduced in Taiwan, with its key components including a ban on herbs containing aristolochic acid, public-awareness campaigns, patient education, funding for CKD research, and the setting up of teams to provide integrated care [36]. In Cuba, the Ministry of Public Health has implemented a national program for the prevention of CKD [37]. It is hoped that the integration of CKD prevention into the NCD program may result in the reduction of renal and cardiovascular risks in the general population. Main outcomes have been the reduction in the prevalence of risk factors, such as low birth weight, smoking, and infectious diseases. There has been an increased rate of diagnosis of diabetes and of glycemic control, increased diagnosis of hypertension, higher rates of blood pressure control and more prescription of renoprotective treatment [38]. Recently, the US Department of Health and Human Services has introduced an ambitious program to reduce the number of Americans developing end-stage renal disease by $25 \%$ by 2030 . The program, known as the Advancing American Kidney Health Initiative, has set goals with metrics to measure its success; among them more efforts to prevent, detect, and slow the progression of kidney disease, in part by addressing traditional risk factors like diabetes and hypertension [39]. Ongoing programs, like the Special Diabetes Program for Indians (SDPI) represents an important part of this approach by providing teambased care and care management. Since its implementation, the incidence of diabetes-related kidney failure among American Native populations decreased by over $40 \%$ between 2000 and 2015 [40].

\section{INVOLVEMENT OF PRIMARY CARE PHYSICIANS AND OTHER HEALTH PROFESSIONALS}

CKD detection and prevention programs require considerable resources and the availability of such resources will depend primarily on the leadership of nephrologists [4I]. However, the number of nephrologists is not sufficient to provide renal care to the growing number of CKD patients worldwide. It has been suggested that most cases of non-progressive CKD can be managed without referral to a nephrologist, and specialist referral can be 
reserved for patients with an eGFR $<30 \mathrm{~mL} / \mathrm{min} / 1.73 \mathrm{~m}^{2}$, rapidly declining kidney function, persistent proteinuria, or uncontrolled hypertension or diabetes [42]. With an educational intervention, the clinical competence of family physicians increases, resulting in preserved renal function in diabetic patients with early renal disease [43]. The results were similar to those found in patients treated by nephrologists [44]. The role of primary health care professionals in the implementation of CKD prevention strategies in LMIC countries has been recently illustrated [45].

\section{SHORTAGE OF NEPHROLOGY MANPOWER - IMPLICATIONS FOR PREVENTION}

The resources for nephrology care remain at critical levels in many parts of the world. Even in Western developed countries, nephrologists are frequently in short supply. In a selection of European countries with similar, predominantly public, health care systems, there was a substantial variation in the nephrology workforce. Countries like Italy, Greece, and Spain reported the highest densities, while countries like Ireland, Turkey and the UK had the lowest [47]. In the USA, the number of nephrologists per 1000 ESRD patients has declined over the years, from 18 in 1997 to 14 in 2010 [48]. The situation in the developing world is even worse. With the exception of Nigeria, Sudan, Kenya and South Africa, in many countries of sub-Saharan Africa there are fewer than 10 nephrologists. The number of nephrology nurses and dialysis technicians is also insufficient [49]. In Latin America the average number of nephrologists is 13.4 pmp. However, there is unequal distribution between countries; those with $<10$ nephrologists pmp include Honduras (2.1 pmp), Guatemala (3.3 pmp) and Nicaragua (4.6 pmp), and those exceeding 25 pmp include Cuba (45.2 pmp), Uruguay (44.2 pmp) and Argentina (26.8 pmp) [50].

The causes of this shortage are multiple. Potential contributors include the increasing burden of CKD, erosion of the scope of nephrology practice by other specialists, lack of workforce planning in some countries, and the development of new care delivery models [48]. A novel strategy has been the successful ISN Fellowship program. Since its implementation in 1985, over 600 fellows from more than 83 LMICs have been trained. A significant number of fellowships were undertaken in selected developed centers within the fellow's own region. In a recent survey, $85 \%$ of responding fellows were re-employed 12 by their home institutions [5।,52].

\section{THE INTERDISCIPLINARY PREVENTION APPROACH}

Since 1994, a National Institute of Health consensus advocated for early medical intervention in predialysis patients. Owing to the complexity of care of CKD, it was recommended that patients should be referred to a multidisciplinary team consisting of nephrologist, dietitian, nurse, social worker, and health psychologist, with the aim to reduce predialysis and dialysis morbidity and mortality [53]. In Mexico, a nurse-led, protocol driven, multidisciplinary program reported better preservation in eGFR and a trend in the improvement of quality of care of CKD patients, similar to those reported by other multidisciplinary clinic programs in the developed world. Additionally, more patients started dialysis non-urgently, and some obtained a pre-emptive kidney transplant. For those unable to obtain dialysis or who choose not to, a palliative care program is now being implemented [54]. Future models should address region-specific causes of CKD, increase the quality of diagnostic capabilities, establish referral pathways, and provide better assessments of clinical effectiveness and cost-effectiveness [55]

\section{ONLINE EDUCATIONAL PROGRAMS FOR CKD PREVENTION AND TREATMENT}

E-learning has become an increasingly popular approach to medical education. Online learning programs for NCD prevention and treatment, including CKD, have been successfully implemented in Mexico. By 2015, over 5000 health professionals (including non-nephrologists) had been trained using an electronic health education platform [46]. It is equally important to promote "Prevention" with education programs for those at risk of kidney disease and with the general population at large. Education is key to engaging patients with kidney disease. It is the path to selfmanagement and patient-centered care. Narva et al. found that patient education is associated with better patient outcomes [56]. Obstacles include the complex nature of kidney disease information, low baseline awareness, limited health literacy and numeracy, limited availability of CKD information, and lack of readiness to learn. New educational approaches should be developed through research and quality improvement efforts. Schatell et al. found that Webbased kidney education is helpful in supporting patient selfmanagement [57]. Reputable healthcare organizations should facilitate easier access to health information on their websites (Appendix I). Engagement of professional society resources and patient groups is a crucial step to promote community partnership and patient empowerment on prevention. 


\section{RENEWED FOCUS ON PREVENTION AND AWARENESS RAISING AND EDUCATION}

Given the pressing urgency pertaining to the need for increasing education and awareness on the importance of the preventive measures, we suggest the following goals to redirect the focus on plans and actions:

(i) Empowerment through health literacy in order to develop and support national campaigns that bring public awareness to prevention of kidney disease.

(ii) Population-based approaches to manage key known risks for kidney disease, such as blood pressure control and effective management of obesity and diabetes.

(iii) Implementation of the WHO "Best Buys" approach including screening of at-risk populations for CKD, universal access to essential diagnostics of early CKD, availability of affordable basic technologies and essential medicines, and task shifting from doctors to front-line healthcare workers to more effectively target progression of CKD and other secondary preventative approaches.

To that end, the motto "Kidney Health for Everyone, Everywhere" is more than a tagline or wishful thinking. It is a policy imperative which can be successfully achieved if policy makers, nephrologists and healthcare professionals place prevention and primary care for kidney disease within the context of their Universal Health Coverage programs.

\section{Supplementary material}

Appendix 1: Selected websites with information on CKD patient education.

\section{Acknowledgments}

The authors would like to thank both the International Society of Nephrology and the International Federation of Kidney Foundations for their support for World Kidney Day.

Members of the World Kidney Day Steering Committee are Philip Kam Tao Li, Guillermo Garcia-Garcia, Sharon Andreoli, Kamyar Kalantar-Zadeh, Latha Kumaraswami, Vassilios Liakopoulos, Siu-Fai Lui, Gamal Saadi, Luisa Strani and Ifeoma Ulasi. Philip KT Li and K Kalantar-Zadeh serve as the corresponding authors. All the authors contributed equally to the conception, preparation, and editing of the manuscript.

\section{Disclosures}

All the authors declared no competing interests.

This article was originally published in Kidney International,
The permission of republication herein was granted by the authors, the journal and its publisher.

\section{REFERENCES}

I. 2019 United Nations High Level Meeting on UHC: Moving together to build kidney health worldwide. Brussels, Belgium: International Society of Nephrology. https://www.theisn.org/images/Advocacy_4_ pager_2019_Final_WEB_pagebypage.pdf. Accessed 20 July 2019.

2. Foreman KJ, Marquez N, Dolgert A, et al. Forecasting life expectancy, years of life lost, and all-cause and cause-specific mortality for 250 causes of death: reference and alternative scenarios for 2016-40 for 195 countries and territories. Lancet. 2018; 392(I0 I 59):2052-2090.

3. Essue BM, Laba TL, Knaul F, et al. Economic burden of chronic ill health and injuries for households in low- and middle-income countries. In: Jamison DT, Gelband H, Horton S, et al., eds. Disease control priorities: improving health and reducing poverty. 3rd ed. Washington, DC: World Bank; 2018. pp 121-143.

4. Vanholder R, Annemans L, Brown E, et al. Reducing the costs of chronic kidney disease while delivering quality health care: a call to action. Nat Rev Nephrol. 2017; I 3(7):393-409.

5. Luyckx VA, Tuttle KR, Garcia-Garcia G, et al. Reducing major risk factors for chronic kidney disease. Kidney Int Suppl. 2017; 7(2):7I-87.

6. Luyckx VA, Tonelli M, Stanifer JW. The global burden of kidney disease and the sustainable development goals. Bull World Health Organ. 2018; 96(6):414-422D.

7. Tonelli M, Muntner P, Lloyd A, et al. Risk of coronary events in people with chronic kidney disease compared with those with diabetes: a population-level cohort study. Lancet. 2012; 380(9844):807-814.

8. Kalantar-Zadeh K, Fouque D. Nutritional management of chronic kidney disease. N Engl J Med. 2017; 377(18): |765-1776.

9. Political declaration of the third high-level meeting of the General Assembly on the prevention and control of non-communicable diseases. United Nations General Assembly; 2018. https://www.un. org/ga/search/view_doc.asp?symbol=A/73/L.2\&Lang=E.

10. Lopez AD, Williams TN, Levin A, et al. Remembering the forgotten non-communicable diseases. BMC Medicines. 20I4; I2:200.

I I. Picture of America Executive Summary. Centers for Disease Control and Prevention; 2019. www.cdc.gov/pictureofamerica.

12. Levey AS, Schoolwerth AC, Burrows NR, et al. Centers for Disease Control and Prevention Expert Panel. Comprehensive public health strategies for preventing the development, progression, and complications of CKD: report of an expert panel convened by the Centers for Disease Control and Prevention. Am J Kidney Dis. 2009; 53(3):522-535.

13. Saran R, Robinson B, Abbott KC, et al. US Renal Data System 2018 Annual Data Report: Epidemiology of kidney disease in the United States. Am J Kidney Dis. 2019; 73(3SI):A7-8.

14. Kovesdy CP, Furth SL, Zoccali C, World Kidney Day Steering Committee. Obesity and kidney disease: hidden consequences of the epidemic. J Ren Nutr. 2017; 27(2):75-77.

15. Tantisattamo E, Dafoe DC, Reddy UG, et al. Current management of acquired solitary kidney. Kidney Int Rep. 2019; 4(9):1205-1218.

16. Webster AC, Nagler EV, Morton RL, Masson P. Chronic Kidney Disease. Lancet. 2017; 389(I0075): 1238-1252.

17. Koppe L, Fouque D. The role for protein restriction in addition to renin-angiotensin-aldosterone system inhibitors in the management of CKD. Am J Kidney Dis. 2019; 73(2):248-257.

18. Rifkin DE, Coca SG, Kalantar-Zadeh K. Does AKI truly lead to CKD? J Am Soc Nephrol. 2012; 23(6):979-984.

19. Torres VE, Chapman AB, Devuyst $O$, et al. Tolvaptan in patients with autosomal dominant polycystic kidney disease. N Engl J Med. 2012; 367(25):2407-24I8. 
20. Verhave JC, Troyanov S, Mongeau F, et al. Prevalence, awareness, and management of CKD and cardiovascular risk factors in publicly funded health care. Clin J Am Soc Nephrol. 20 I4; 9:7। 3-7I9.

21. Chow KM, Szeto CC, Kwan BCH, Leung CB, Li PK. Public lacks knowledge on chronic kidney disease: telephone survey. Hong Kong Med J. 2014; 20:139-144.

22. Ene-lordache B, Perico N, Bikbov B et al. Chronic kidney disease and cardiovascular risk in six regions of the world (ISN-KDDC): A cross-sectional study. Lancet Glob Health. 2016; 4:e307-319.

23. Li PKT, Weening JJ, Dirks J, et al. A report with consensus statements of the International Society of Nephrology 2004 Consensus Workshop on Prevention of Progression of Renal Disease, Hong Kong, June 29, 2004. Kidney Int Suppl. 2005; (94):S2-7

24. Vassalotti JA, Stevens LA, Levey AS. Testing for chronic kidney disease: A position statement from the National Kidney Foundation. Am. J. Kidney Dis. 2007; 50:169-180.

25. Levey AS, Atkins R, Coresh J, et al. Chronic kidney disease as a global public health problem: approaches and initiatives - a position statement from Kidney Disease Improving Global Outcomes. Kidney Int. 2007; 72:247-259.

26. Crowe E, Halpin D, Stevens P; Guideline Development Group. Early identification and management of chronic kidney disease: summary of NICE guidance. BMJ. 2008; 337:al 530.

27. Li PKT, Chow KM, Matsuo S, et al. Asian chronic kidney disease best practice recommendations: Positional statements for early detection of chronic kidney disease from Asian Forum for Chronic Kidney Disease Initiatives (AFCKDI). Nephrology (Carlton). 20I I; 16(7):633-641.

28. Fink HA, Ishani A, Taylor BC, et al. Screening for, monitoring, and treatment of chronic kidney disease stages I to 3: A systematic review for the U.S. Preventive Services Task Force and for an American College of Physicians Clinical Practice Guideline. Ann Intern Med. 2012; |56:570-581.

29. Li PKT, Ng JK, Cheng YL, et al. Relatives In Silent Kidney disease Screening study (RISKS): a Chinese cohort study. Nephrology (Carlton). 2017; 22(Suppl 4):35-42.

30. Samal L, Linder JA. The primary care perspective on routine urine dipstick screening to identify patients with albuminuria. Clin J Am Soc Nephrol. 20 I3; 8(I): I31-135.

31. George C, Mogueo A, Okpechi I, Echouffo-Tcheugui JB, Kengne AP. Chronic kidney disease in low-income to middle-income countries: the case for increased screening. BMJ Glob Health. 2017; 2(2):e000256.

32. Gonzalez-Quiroz M, Nitsch D, Hamilton S, et al, DEGREE Study Steering Committee. Rationale and population-based prospective cohort protocol for the disadvantaged populations at risk of decline in eGFR (CO-DEGREE). BMJ Open. 2019; 9:e03। I69.

33. Boulware LE, Jaar BG, Tarver-Carr ME, Brancati FL, Powe NR. Screening for proteinuria in US adults: A cost-effectiveness analysis. JAMA. 2003; 290:3101-31|4.

34. Go DS, Kim SH, Park J, Ryu DR, Lee HJ, Jo MW. Cost-utility analysis of the National Health Screening Program for chronic kidney disease in Korea. Nephrology (Carlton). 2019; 24(I):56-64.

35. Komenda P, Ferguson TW, Macdonald K, et al. Cost-effectiveness of primary screening for CKD: A systematic review. Am J Kidney Dis. 2014; 63:789-797.

36. Hwang SJ, Tsai JC, Chen HC. Epidemiology, impact and preventive care of chronic kidney disease in Taiwan. Nephrology (Carlton). 2010; 15(Suppl 2):3-9.

37. Almaguer M, Herrera R, Alfonso J, Magrans C, Mañalich R, Martínez A. Primary health care strategies for the prevention of end-stage renal disease in Cuba. Kidney Int Suppl. 2005; 97:S4-10.

38. Alamaguer-Lopez M, Herrera-Valdez R, Diaz J, Rodriguez $\bigcirc$. Integration of chronic kidney disease prevention into noncommunicable disease programs in Cuba. In Garcia-Garcia G, L. Agodoa LY, \& Norris KC, editors. Chronic kidney disease in disadvantaged populations. London, UK: Elsevier; 2017. pp. 357-365.
39. Advancing American Kidney Health. U.S. Department of Health and Human Services; 2019. https://aspe.hhs.gov/pdf-report/advancingamerican-kidney-health. Accessed 26 September 2019.

40. The Special Diabetes Program for Indians: estimates of Medicare savings. U.S. Department of Health and Human Services; 2019. https://aspe.hhs.gov/pdf-report/special-diabetes-program-indiansestimates-medicare-savings Accessed 26 September 2019.

4I. Bello AK, Nwankwo E, El Nahas AM. Prevention of chronic kidney disease: a global challenge. Kidney Int Suppl. 2005; 98:S I I-17.

42. James MT, Hemmelgarn BR, Tonelli M. Early recognition and prevention of chronic kidney disease. Lancet. 2010; 375(9722): I 296-1309.

43. Cortés-Sanabria L, Cabrera-Pivaral CE, Cueto-Manzano AM, et al. Improving care of patients with diabetes and CKD: a pilot study for a cluster-randomized trial. Am J Kidney Dis. 2008; 5 I (5):777-788.

44. Martínez-Ramírez HR, Jalomo-Martínez B, Cortés-Sanabria L, et al. Renal function preservation in type 2 diabetes mellitus patients with early nephropathy: a comparative prospective cohort study between primary health care doctors and a nephrologist. Am J Kidney Dis. 2006; 47( I):78-87.

45. Cueto-Manzano AM, Martínez-Ramírez HR, Cortes-Sanabria L, Rojas-Campos E. CKD screening and prevention strategies in disadvantaged populations. The role of primary health care professionals. In Garcia-Garcia G, L. Agodoa LY, \& Norris KC, editors. Chronic kidney disease in disadvantaged populations. London, UK: Elsevier; 2017. pp. 329-335

46. Tapia-Conyer R, Gallardo-Rincon H, Betancourt-Cravioto M. Chronic kidney disease in disadvantaged populations: Online educational programs for NCD prevention and treatment. In Garcia-Garcia G L. Agodoa LY, \& Norris KC, editors. Chronic kidney disease in disadvantaged populations. London, UK: Elsevier; 2017. pp. 337-345.

47. Bello AK, Levin A, Manns BJ, et al. Kidney Health for Life Initiative. Effective CKD care in European countries: challenges and opportunities for health policy. Am J Kidney Dis. 20 I5; 65(I): I5-25.

48. Sharif MU, Elsayed M E, Stack AG. The global nephrology workforce: emerging threats and potential solutions! Clin Kidney J. 2016; $9(1): 11-22$

49. Naicker S, Eastwood JB, Plange-Rhule J, Tutt RC. Shortage of healthcare workers in sub-Saharan Africa: a nephrological perspective. Clin Nephrol. 20 I0; 74(Suppl I):S129-133.

50. Cusumano AM, Rosa-Diez G], Gonzalez-Bedat MC. Latin American Dialysis and Transplant Registry: Experience and contributions to end-stage renal disease epidemiology. World J Nephrol. 2016; 5(5):389-397.

5।. Feehally J, Brusselmans A, Finkelstein FO, et al. Improving global health: measuring the success of capacity building outreach programs: a view from the International Society of Nephrology. Kidney Int Suppl. 2016; 6(2):42-5।.

52. Harris DC, Dupuis S, Couser WG, Feehally J. Training nephrologists from developing countries: does it have a positive impact? Kidney Int Suppl. 2012; 2(3):275-278.

53. Tisher CC, Bastl CP, Bistrian BR, et al. Morbidity and mortality of renal dialysis: an $\mathrm{NIH}$ consensus conference statement. Ann Intern Med. 1994; 121 ( I):62-70.

54. Garcia-Garcia G, Martinez-Castellanos Y, Renoirte-Lopez K, et al. Multidisciplinary care for poor patients with chronic kidney disease in Mexico. Kidney Int Suppl. 2013; 3(2): I78-183.

55. Stanifer JW, Von Isenburg M, Chertow GM, Anand S. Chronic kidney disease care models in low- and middle-income countries: a systematic review. BMJ Glob Health. 20 18; 3(2):e000728.

56. Narva AS, Norton JM, Boulware LE. Educating Patients about CKD: the path to self-management and patient-centered care. Clin J Am Soc Nephrol. 20 I 6; 7; I I (4):694-703.

57. Schatell D. Web-based kidney education: supporting patient self-management. Semin Dial. 2013; 26(2): I54-158. 